\title{
Influence of the educational level on the spreading of Fake News regarding the energy field in the online environment
}

\author{
Mihai-Ionuț POP \\ Bucharest University of Economic Studies, Romania \\ E-mail: mihai.pop@digitix.ro \\ Irina ENE \\ Bucharest University of Economic Studies, Romania \\ E-mail: irina3ene@yahoo.com
}

PICBE |

\begin{abstract}
For the last couple of decades, the social and economic dynamics of our society have evolved in an exponential rhythm creating innovation and new opportunities which contribute to social welfare and comfort. Unfortunately, this continued progress, especially in the field of digitalisation, is also accompanied by challenges. One of these refers to cybersecurity and the uncontrolled spreading of fake content. The emergence of the Internet, alongside the development of new communication instruments and platforms, has determined major changes in the way people interact with each other. Moreover, the structure of the online environment facilitates the spreading of unverified or false content. Even specialized fields like the wood industry, the banking sector, the pharmaceutical industry or the energy field can become targets of misinformation campaigns, implemented in the online environment. Furthermore, in a context in which, in recent years, major political, economic and social events have been negatively influenced by the dissemination of fake news, the combat of this phenomenon has become a priority on the European Agenda. This fact is being reinforced by the growing number of scientific articles and researches that address this issue, but also by the budget of almost 5 million euro allocated in 2018 by the European Union for the combat of misinformation and false news. In this regard, it is important to better understand the factors that determine the appearance and spreading of fake news. By analysing the roots, the main sources and the patterns of fake news, we will be able to elaborate efficient tools in order to fight against the spreading of this phenomenon. The objective of this study is to analyse if the educational level of online users is one of the factors which directly influences the acceptance and the spreading of fake news, especially when dealing with specialized content such as information regarding the Romanian energy field.
\end{abstract}

Keywords: Fake news, misinformation, social media, educational level, energy

\section{Introduction}

The dynamics of the world we live in and the events which take place around us have a direct influence on our activity and social behavior. The information which one encounters on daily basis can affect one's opinion and indirectly one's decisions and actions, especially if individuals who are behind the source, from which the content is presented, have the objective of manipulating the public opinion in order to determine a given reaction.

Recent debates on the digital age emphasis that anyone can involuntary become a victim of fake news, regardless if as main target of an implemented manipulation campaign build around the spreading of false content, or as part of the audience which interacts with the fake content. By spreading false information or news about public figures, companies or state institutions, the image, career, or even personal life of those who are being targeted by a negative campaign can irremediable be affected. 
Unfortunately, we live in a world lacking stability and predictability, which is dominated by major changes, that negatively contribute to the general well-being and cause political tensions on international level, creating confusion and distrust. Despite the technological progress in all areas of activity, synchronized with a facilitated access to information, we can observe that for the last couple of years events and debates, that determine social imbalances, are regularly being promoted. Because of the fact that the public space is invaded by such a large number of information, statements and news, individuals are kept captive in a situation in which the proofing and evaluation of all online encountered content is impossible. This phenomenon is promoted through social media platforms and online media. Paradoxically, the platforms, which have been created to facilitate communication and interpersonal relationships, are now frequently being used to divide and manipulate the public opinion.

In recent years, and even at the 2018th Helsinki summit, attended by the US and Russian presidents, the subject regarding the appearance and spreading of fake news has been widely debated, alongside the negative effects of this phenomenon. Both, world leaders and specialists from all fields of activity, have grasped the seriousness and the repercussions associated with the promotion of fake news (BBC, 2018). False information has the ability to affect the image of public figures, companies, specialized industries, or even to negatively influence legislative processes or essential democratic processes.

The importance of fighting against this negative phenomenon is reinforced by the increasing number of scientific articles and researches, which address this issue, but also by the budget of almost $€ 5$ million allocated by the European Union in 2018 in order to combat misinformation and fake news (Marin, 2018).

This paper aims to establish if there is a relation between the educational level of online users and the spreading of fake news specific content regarding a specialized economic field, like the energy sector.

\section{Literature review}

In recent years, the worldwide society has adapted in a dynamic manner to new technologies, which reached and redefined most of the economic, politic and social fields. Gradually, the vast majority of individuals have transferred their communication activity on the internet. Whether we are referring to interpersonal, B2C or B2B communication, the digital space, and especially, the social media platforms have exponentially gained importance during the last decade. Social media has enabled the development of new attractive methods and instruments, which allow individuals to communicate within the online environment, to group in online communities of interest and to transfer information in an easy, quick and useful way.

Studies of recent years show that social media has become an interesting phenomenon respectively an attractive research topic. According to Angelo (2007), social media has a wider meaning, which usually is defined as unconventional or untraditional media. In comparison to traditional media, social media users are co-creators of content. They contribute with their own believes, reviews, ideas and opinions to the creation, spreading or sharing of online content. Scott (2010) points out, that individuals, who are active on social media platforms, have the possibility to use these instruments in order to share, appreciate or bring a personal input to the online available content. As mentioned 
above, in comparison to traditional media, such as newspaper, radio or television, on social media platforms, users can actively contribute to the creation process of content and determine its spreading.

Jucaityte and Mašcinskiene (2014) note that one of the major advantages of the online communication process is represented by the variety of platforms it offers (forums, blogs, websites, messengers, communities, social platforms), which allow Internet users to choose a suitable platform for sharing or exchanging ideas and information. Authors point out that the increasing number of social media users has determined major changes in the communication dynamics between companies and customers. Social media offers communication and marketing tools that help companies reach their potential or existing clients and create, present or sell their products in a specific form that is shaped on the consumers' needs (Jucaityte \& Mašcinskiene, 2014). Furthermore, by implementing an optimal social media marketing strategy, which facilitates a direct and efficient communication, companies can increase sales. Moreover, organizations should adapt their communication strategies in order to better integrate the social media platforms in the marketing or client service activities. By doing this, an increased brand visibility and a better relation with the stakeholders will be ensured (Jucaityte \& Mašcinskiene, 2014).

Furthermore, within a company and under optimum conditions, social media tools can contribute to the improvement of various organizational dimensions, including the communication processes, community development systems, information flows, promotion of the company's values or culture and even collective intelligence (Badea, 2014).

Recent studies show that communication and marketing strategies implemented on social media platforms should include the same elements as the ones applied on traditional media. These include target audience, objectives, content strategies, communication pillars or channels and budget.

Unfortunately, the Internet, together with the new means of digital communication, has brought not only opportunities, like offering companies the possibility to reach their maximum marketing potential, to better communicate with clients or even directly exchange ideas, feedback and information with internet users, but is also associated with negative aspects, which refer to fake reviews, misinformation and fake news. In this context, both companies, as well as, Internet users can easily become the victims of fake news or fake reviews.

Munzel (2016) notes "as consumers increasingly interact with each other over the internet and exchange opinions and experiences on various service encounters, firms are increasingly devoting resources to monitoring, analyzing, repairing, and improving their reputations online. While many ORM firms are legitimate, providers are increasingly adopting deceptive practices, such as publishing fake reviews."

Studies define these fictive reviews as being written with the objective of sounding authentic in order to deceive internets users and determine them to take a given action (Ott, Cardie, Hancock, 2012). Furthermore, estimates suggest that approximatively one third of the existing online reviews are fake (Streitfeld, 2012). Unfortunately, the increasing number of fake reviews does not only jeopardize the opportunity for companies to improve their services or products in compliance with the costumers' feedback, but it also affects the quality of the research and information process conducted online by potential customers (Munzel, 2016). 
The risks associated with social media should be analyzed in relation with the fact that individuals use social platforms, not only for entertainment and communication, but also in their daily process of gathering important information. In this context, social media platforms facilitate the spreading and sharing of unverified content and information, which in some cases prove to be untrue (Friggeri, et al., 2014). Fake news has the ability of generating high engagement on social media while confusing individuals, who receive their daily information through online platforms. (Lewandowsky, et al., 2010).

Jang et al. (2018) defines fake news as fabricated information created and spread through social media platforms in order to deceive the public opinion and achieve economic, political or ideological gains. Usually, fake news takes the form of distorted information, which is presented in a humoristic, sarcastic or provocative manner, in order to attract and raise engagement in online communities (Figueira, Oliveira, 2017). Studies point out that the major part of fake content, promoted in the online environment, is generated by fake or anonymous websites, that have similar domain names as renowned news platforms (Figueira, Oliveira, 2017).

A research conducted by Warner-Søderholm et al. (2018) shows that only $20 \%$ of the respondents of the study trust the information and news they reed on social media platforms. Trust can be defined as a set of beliefs that the other party will hold back on taking advantage of a situation and will avoid having an opportunistic behaviour (Ridings et al. 2002). In this context, Warner-Søderholm et al. (2018) note that trust on social media can be defined as the personal confidence of individuals regarding other online users or social platforms. In many situations, online users, that are active on social media platforms, seek confirmations and support from their virtual friends or in online communities. They perceive care and love as well as emotional, moral, social, and informational support (Ridings \& Gefen, 2004).

This fact emphasizes the importance of trust on social media platforms and suggests that it is critical for news platforms, online users, companies and public institutions to find optimal tools for combating the negative phenomenon of fake news.

Recent studies note that national culture (Pelau \& Pop, 2018) and demographic criteria play a major role regarding the acceptance and spreading of fake news. Tantau et al. (2018) point out that young women are less likely to spread fake news in comparison to men. Furthermore, other authors show that women and young users have higher expectations for integrity and trust regarding other individuals (Warner-Søderholm et al., 2018).

In this perspective, we consider that the phenomenon of fake news has to further be researched and we are convinced that through a better understanding of its roots and spreading patterns, we will be able to elaborate specific tools in order to combat its negative effects.

In this paper we examine if the educational level of online users plays a role in the spreading and acceptance of fake news, especially when this refers to information regarding the energy field, an economic sector of great importance.

\section{Methodology}

A study conducted by Tantau et al. (2018) proved that demographic criteria play an important role in the acceptance and spreading of fake news, especially when it covers subjects related to specific and specialized activity areas, such as the energy sector. In this context, the objective of the research presented in this paper is to determine if the 
educational level of online users, which are active on social media platforms, can influence the spreading degree of fake news related to an important economic sector, such as the energy field.

Furthermore, the paper focuses on establishing if social media users with different educational levels generate different reactions to the same type of content posted in a fake news specific manner. Moreover, we have tested the formulated hypothesis referring to the fact that a post written in a fake news specific manner will generate a higher engagement among Internet users, who declared a lower educational level. In order to test our hypothesis, we have selected a link to an article referring to the analysis of the evolution of the natural gas prices in Romania commented by the Chairman of the Romanian Industry and Services Committee (Buican, 2018). Based on this interview, we have formulated the following Facebook post description in a fake news specific manner that included false information, which did not appear in the mentioned article:

"ROMANIA on the verge of a DISASTER! Historical growth! The price of natural gas has tripled! How will our invoices change in the coming years? How many Romanians will freeze in winter because of the lack of money?! Below all you need to know". As can be seen, the second copy included a call to action, namely, users were suggested to access the link to the interview.

One can observe that this post was written in a fake news or click-bait specific way. To test the formulated hypothesis, this Facebook post was simultaneously promoted through two campaigns. Both campaigns have been boosted for two days, having the same budget, but different audiences. Each campaign has spent 40 RON (about 9 euro) and targeted men and women with the age of 35 or more, who are living in Romania, but have different educational backgrounds. On one hand, through the first campaign, we have targeted Facebook users, who have registered a higher educational level, for example bachelor's, master's or doctoral degrees, while on the other hand, the second campaign has targeted people with a lower educational level, who only declared having high school degrees. Moreover, both campaigns had the same objective, namely the optimization of the post engagement.

\section{Results}

The generated results reinforced our hypothesis that individuals with a lower educational level are more likely to disseminate the copy, which was written in a fake news specific form.

As observed in table no. 1, the post reached 11.218 relatively less educated users and only 8.842 individuals with a relatively higher education. Furthermore, the hypothesis is also supported by the lower CPE generated by the campaign, which has targeted less educated Facebook users. In this context, the cost per engagement was 33\% higher for the campaign, that has reached individuals with a higher educational level. Furthermore, this campaign has generated only 888 interactions, in comparison to the other campaign, which has registered 1.213 post engagements.

More precisely, with the same budget, the campaign that has targeted Facebook users, who only declared having a high school degree, has generated $36,6 \%$ more interactions than the campaign, which has reached individuals with a higher educational level. 
Table no. 1. Reach and post engagement registered by the two implemented campaigns on social media networks depending on educational level of the users

\begin{tabular}{|c|c|c|c|c|}
\hline & Reach & Post engagement & Budget in RON & CPE \\
\hline relatively more educated individuals & 8.842 & 888 & 40 & 0,04 \\
\hline relatively less educated individuals & 11.218 & 1.213 & 40 & 0,03 \\
\hline
\end{tabular}

PICBE |

Source: Authors own research results

On the basis of figure no.1, one can observe that gender plays a very important role in the dissemination of news related to the energy field. Compared to the number of women, 1.107 more men have interacted with the post.

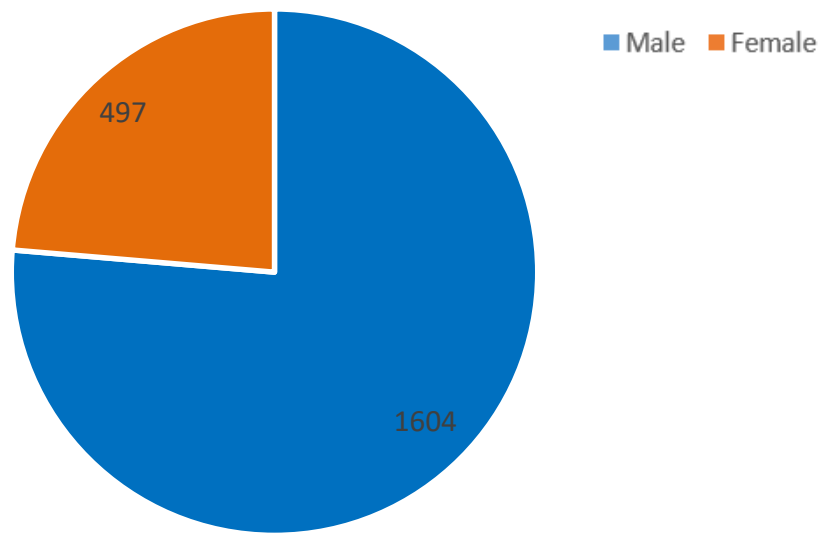

Fig. no. 1. Post engagement by gender

Source: Authors own research results

Furthermore, as can be seen, figure no. 2 supports the hypothesis that men have a higher probability of interacting with energy related topics, in comparison to women. This is emphasized by the fact that the two campaigns reached 4.274 women and 15.776 men. These results reinforce the idea that men have a higher acceptance of news related to the energy sector. 


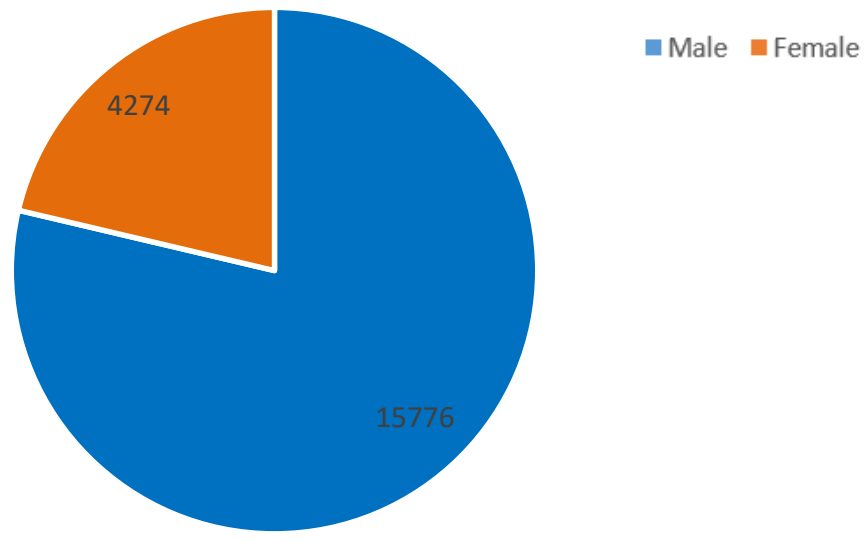

PICBE |

Fig. no. 2. Reach by gender

Source: Authors own research results

The results were also analyzed in relation to the age and the gender of the targeted individuals. It has been found that women in the 35-44 age interval, regardless of education level, have generated the lowest number of interactions regarding the post in comparison to the other age groups. For this gender-age category, energy related topics seem to be relatively unimportant. In the other extreme, men with ages over 65 years have registered the highest number of interactions with the published post. Furthermore, it has been proven that in the 55-64 age range, the educational level plays a significant role in the dissemination of fake news. As a result, it has been established that individuals with a higher educational level, belonging to the mentioned interval, have generated $56 \%$ fewer interactions in comparison to other gender-age categories.

Furthermore, table no. 2 points out that women with a higher educational level and ages between 35 and 44 years have registered the lowest engagement rate. This age-gender interval lead to the highest registered difference between individuals with higher educational level and ones that have only declared having high school degree.

Table no. 2. Impressions and post engagement on social media networks depending on demographic category and educational level

\begin{tabular}{|c|c|c|c|c|c|c|c|c|}
\hline \multirow[t]{2}{*}{ User category } & \multicolumn{3}{|c|}{ Impressions } & \multicolumn{3}{|c|}{ Post engagement } & \multicolumn{2}{|c|}{$\begin{array}{l}\text { Engagement rate } \\
(\%)\end{array}$} \\
\hline & $\begin{array}{c}\text { relative } \\
\text { ly more } \\
\text { educate } \\
d \\
\text { individ } \\
\text { uals } \\
\end{array}$ & $\begin{array}{c}\text { relative } \\
\text { ly less } \\
\text { educate } \\
d \\
\text { individ } \\
\text { uals } \\
\end{array}$ & $\begin{array}{l}\text { Diff. } \\
(\%)\end{array}$ & $\begin{array}{c}\text { relative } \\
\text { ly more } \\
\text { educate } \\
d \\
\text { individ } \\
\text { uals } \\
\end{array}$ & $\begin{array}{c}\text { relative } \\
\text { ly less } \\
\text { educate } \\
\text { d } \\
\text { individ } \\
\text { uals g } \\
\end{array}$ & $\begin{array}{l}\text { Diff. } \\
(\%)\end{array}$ & $\begin{array}{c}\text { relative } \\
\text { ly more } \\
\text { educat } \\
\text { ed } \\
\text { individ } \\
\text { uals } \\
\end{array}$ & $\begin{array}{c}\text { relative } \\
\text { ly less } \\
\text { educate } \\
d \\
\text { individ } \\
\text { uals } \\
\end{array}$ \\
\hline Male, age $35-44$ & 2963 & 1919 & $-35 \%$ & 203 & 120 & $69 \%$ & 0,08 & 0,07 \\
\hline Male, age $45-54$ & 2274 & 3059 & $35 \%$ & 194 & 254 & $-24 \%$ & 0,10 & 0,10 \\
\hline Male, age 55-64 & 1766 & 3689 & $109 \%$ & 160 & 365 & $-56 \%$ & 0,11 & 0,12 \\
\hline Male, age $65+$ & 1071 & 1752 & $64 \%$ & 128 & 180 & $-29 \%$ & 0,14 & 0,12 \\
\hline Female, age $35-44$ & 177 & 70 & $-60 \%$ & 2 & 5 & $-60 \%$ & 0,01 & 0,08 \\
\hline Female, age $45-54$ & 434 & 351 & $-19 \%$ & 38 & 34 & $12 \%$ & 0,09 & 0,11 \\
\hline
\end{tabular}




\begin{tabular}{|c|c|c|c|c|c|c|c|c|}
\hline Female, age 55-64 & 1020 & 1511 & $48 \%$ & 99 & 171 & $-42 \%$ & 0,11 & 0,13 \\
\hline Female, age 65+ & 516 & 807 & $56 \%$ & 64 & 84 & $-24 \%$ & 0,14 & 0,12 \\
\hline
\end{tabular}

Source: Authors own research results

Table no. 3 shows that the campaign, which has targeted individuals with a higher educational level, has generated lower scores than the other campaign. To put it briefly, relatively less educated individuals have registered 30\% more link click and 37\% more interactions with the post in comparison to the relatively more educated audience.

Table no. 3. Reach and link clicks on social media networks depending on educational level

\begin{tabular}{|c|c|c|c|}
\hline Ad type & Post Engagement & Link clicks & $\begin{array}{l}\text { Unique Link } \\
\text { Clicks }\end{array}$ \\
\hline Relatively more educated individuals & 888 & 520 & 512 \\
\hline Relatively less educated individuals & 1213 & 677 & 655 \\
\hline Differences & 0,37 & 0,30 & 0,28 \\
\hline
\end{tabular}

Source: Authors own research results

In conclusion, the tested hypothesis revealed that the educational level has a direct impact on the spreading of fake news and that less educated internet users, which are active on social media platforms, are more likely to interact and share fake information.

\section{Conclusion}

The acceptance and spreading of fake news has become a priority on the agenda of important European countries. Debates on this issue revealed the risks associated with the spreading of this phenomenon. As mentioned earlier in the paper, fake news can affect the reputation of public figures, companies or state institutions and negatively influence their professional, economic and social activities. Moreover, it can create social imbalance, influence the public opinion and interfere in major legislative or democratic processes. The importance of fighting against this negative phenomenon is reinforced by the budget of almost $€ 5$ million allocated by the European Union in 2018 in order to combat misinformation and fake news, but also by the increasing number of scientific articles and researches, which address this issue (Marin, 2018).

The results of our study reinforced the hypothesis that the educational level of Internet users, who interact with false content in the online environment, has a direct influence on the acceptance and spreading degree of fake news. Our research has emphasized that young educated individuals have a lower probability of sharing unverified information. Furthermore, the study conducted by Tantau et al. (2018) points out that age and gender play a significant role in the acceptance and spreading of fake news. In this context, young women are less likely to spread false information in the online environment.

The limitations of our study refer to the fact that the targeted audiences within our research area were reached on the basis of their personal declared educational level. The formulated hypothesis will be further tested in future studies, alongside other factors, which contribute to the spreading of fake news in the online environment.

We believe that through a better understanding of the objectives, roots and sources, which led to the appearance of this phenomenon, we will be able to develop the necessary 
instruments of fighting against misinformation in the virtual environment. As the paper points out, a high educational level is a major factor in the combat of fake news. Through the implementation of awareness campaigns regarding this type of content, Internet users could acknowledge the risks associated with fake news and develop personal verification systems in order to evaluate the online encountered content.

\section{References}

Angelo, F., (2007). Social media change the rules. Communication World, 24, 9-10.

BBC, (2018). Trump sides with Russia against FBI at Helsinki summit. Retrieved from: https://www.bbc.com/news/world-europe-44852812, on 27.11.2018.

Badea, M., (2014). Social Media and Organizational Communication. Faculty of Political Sciences, Letters and Communication, Valahia University of Târgoviște, 34-36.

Buican, A., (2018). Iancu: Am ajuns să înregistrăm o creștere a preţului la gaze naturale cu peste 48\% într-un singur an, Revista capital. Retrieved from: http://www.capital.ro/iancuromania-are-o-performanta-negativa-fara-precedent-la-nive.html, on 17.04.2018.

Figueira, A., Oliveira, L., 2017. The current state of Fake News: Challenges and Opportuniteis, Procedia Computer Science, 121, pp. 817-825.

Friggeri, A., Adamic, L. A., Eckles, D., Cheng, J., (2014). Rumor Cascades. In Proceedings of the Eighth International AAAI Conference on Weblogs and Social Media.

Jang, M., Geng T., Queenie Li J.Y., Xia, R., Huang, C.T., Kim, H., Tang, J., 2018. A computational approach for examining the roots and spreading patterns of fake news: Evolution tree analysis, Computers in Human Behavior, 84, pp. 103-113.

Jucaityte, I., Mašcinskiene, J., (2014). Peculiarities of social media integration into Marketing Communication, Economics and Management. ICEM 2014, 23-25.

Lewandowsky, S., Ecker, U. K. H., Seifert, C., Schwarz, N., \& Cook, J. (2012). Misinformation and its correction: Continued influence and successful debiasing. Psychological Science in the Public Interest, 13, 106-131.

Marin, V., (2018): UE se dotează cu un sistem de alertă rapidă pentru combaterea dezinformării, Adevarul.ro. Retrieved from: https://adevarul.ro/international/ europa/ue-doteaza-sistem-alerta-rapida-combaterea-dezinformarii1_5c08c66cdf52022f752be8b6/index.html, on 17.12.2018.

Munzel, A., (2016). Assisting consumers in detecting fake reviews: The role of identity information disclosure and consensus. Journal of Retailing and Consumer Services 32, 96-108.

Ott, M., Claire, C., Hancock J., (2012). Estimating the Prevalence of Deception in Online Review Communities. Conference Estimating the Prevalence of Deception in Online Review Communities, 2187864:ACM. 201-210.

Park, J. H., Gu, B., Leung, A. C. M., \& Konana, P. (2014). An investigation of information sharing and seeking behaviors in online investment communities. Computers in Human Behavior, 31, 1-12.

Pelau, C., Pop, N.Al., (2018). Implications for the energy policy derived from the relation between the cultural dimensions of Hofstede's model and the consumption of renewable energies. Energy Policy, 118, pp. 160-168.

Ridings, C. M., Gefen, D., Arinze, B. (2002). Some antecedents and effects of trust in virtual communities. The Journal of Strategic Information Systems, 11(3), 271-295. 
Ridings, M. C., Gefen, D. (2004). Virtual community Attraction: Why people hang out online. Journal of Computer-mediated Communication, 10(1)

Scott, D. M. (2010). The New Rules of Marketing and PR: How to use Social Media, Blogs, News Releases, Online Video, and Viral Marketing to reach buyers directly. Hoboken, New Jersey, John Wiley \& Sons, Inc.

Streitfeld D., (2012). The Best Book Reviews Money Can Buy, New York Times. Retrieved from: https://www.nytimes.com/2012/08/26/business/book-reviewers-for-hiremeet-a-demand-for-online-raves, on 25.11.2018.

Tanţau, A.D., Chinie, A.C., Borisov, D., (2017), Triggering events for corporate entrepreneurship leading to investments in renewable energy. Environmental Engineering \& Management Journal, 16(12), pp. 2857-2868.

Tanțău, A.D.; Pelau, C.; Pop, M. (2018): Fake news in the energy industry, Fourth BASIQ International Conference on New Trends in Sustainable Business and Consumption (BASIQ), Heidelberg, Germany, 11-13 June 2018.

Warner-Søderholm, G., Bertsch, A., Sawe, E., Lee, D., Wolfe, T., Meyer, J., Engel, J., Fatilua, U.N., (2018). Who trusts social media?, Computers in Human Behavior, 81, 303-315 